\title{
Bioactive Compounds and Quality Attributes of Edible Coated Ready-to- Eat Arils of Pomegranate cv. Bhagwa Packed in Clamshells during Storage
}

\author{
M. Viswanath*, K. Venkataramudu, B. Srinivasulu, K. Swarajya Lakshmi, \\ K. Gopal and M. Balakrishna
}

Department of Fruit Science, Horticultural College and Research Institute, Dist.-Kadapa 516 105, Dr. Y.S.R. Horticultural University, Venkataramannagudem West Godavari, Dist (Andhra Pradesh), India

*Corresponding author

\section{A B S T R A C T}

Keywords

Arils of

pomegranate,

Chitosan, Honey,

Aloevera gel and

storage

temperatures

Article Info

Accepted:

10 November 2018

Available Online:

10 December 2018
The present research study focuses on organic edible coatings such as chitosan $(1 \%)$, aloe vera gel $(100 \%)$, honey $(10 \%)$ as an substitute for chemical based coatings showed promising results in extending shelf life of ready-to-eat arils of pomegranate cv. Bhagwa packed in clamshells. Chitosan $(1 \%)$ treated pomegranate arils packed in clamshells and stored at cold temperature of $4 \pm 1^{\circ} \mathrm{C}$ was found to be promising to maintain several quality parameters such as total anthocyanins (25.38 mg $\left.100 \mathrm{~g}^{-1}\right), \beta-$ carotene content $\left(25.56 \mu 100 \mathrm{~g}^{-1}\right)$ and sensory characters like colour, taste and flavour of arils besides keeping the microbial load at minimum level at twenty days of storage.

\section{Introduction}

Pomegranate (Punica granatum L.) which is regarded as the 'Fruit of paradise' and 'Elixir of life' is one of the choicest table fruit cultivated in India on commercial scale. The edible part of the fruit comprises juicy arils which range from 50 to $70 \%$ of the fruit. Pomegranate arils are juicy and rich in anthocyanins and other phenolic compounds. Scientific evidence has linked increasing consumption of pomegranate arils to improved human health as a result of active phenolic compounds which have potent pharmacological activities (Vinda-Martos et al., 2010). Further, pomegranate arils are an excellent dietary source rich in organic acids, anthocyanins, vitamin-C, fatty acids and mineral elements (Fawole and Opara, 2012). Production of pomegranate arils in 'ready-toeat' form would be a convenient and desirable alternative to the consumption of fresh fruits and may increase pomegranate demand by consumers. However, maintaining the nutritional quality of pomegranate arils is a major challenge because arils easily deteriorate in texture, colour together with an 
increasing in microbial and fungal spoilage.

Minimally processed pomegranate arils have greatly reduced postharvest life compared with whole fruits. It is therefore important to try and improve the preservation and quality of minimally processed arils in order to extend their shelf life. Recent advances in postharvest treatments include, the use of organic edible coatings comprising polysaccharides (cellulose and its derivatives, starch and its derivatives, resins) chitosan, aloe vera gel, honey etc. are of great significance in reducing the post- harvest losses.

The present study was conducted to determine if edible coatings and storage temperatures could be an alternate way to preserve the minimally processed pomegranate arils, with reduced microbial population and extend the shelf life.

\section{Materials and Methods}

Well developed Bhagwa fruits at optimum stage of maturity, free from pest and disease attack were harvested from the field and brought to the laboratory. The arils from fruits were extracted manually after splitting the fruits with the help of sterilized knife. The entire process of aril extraction and packing was done under hygienic conditions. Edible coatings viz., Chitosan (1\%), Aloe vera gel (100\%) and Honey (10\%) were used for treating the arils. The treated arils packed in clamshells were kept at $4 \pm 1^{\circ} \mathrm{C}, 7 \pm 1^{\circ} \mathrm{C}$ and room temperature $\left(26-29^{\circ} \mathrm{C}\right)$.

\section{Preparation of edible coatings}

Chitosan (1\%): Chitosan with 90\% deacetylation and a molecular weight of 360 $\mathrm{kDa}$ was prepared at $1 \%(\mathrm{w} / \mathrm{v})$ concentration in an aqueous solution of acetic acid $(0.5 \%$ $\mathrm{v} / \mathrm{v})$. The solution was warmed to $45^{\circ} \mathrm{C}$ and stirred for complete dissolution of chitosan, adjusting its $\mathrm{pH}$ to 5.2 with $\mathrm{NaOH}$. After cooling at $20^{\circ} \mathrm{C}$, the arils were dipped in the chitosan solution for 60 seconds to generate a uniform film.

Aloe vera (100\%): Matured leaves from Aloe vera plant were harvested and washed with a mild chlorine solution of $25 \%$. Aloe vera gel matrix was then separated from the outer cortex of leave and this colourless hydro parenchyma was ground in a blender. The resulting mixture was filtered to remove the fibres. The gel matrix was pasteurized at $70^{\circ} \mathrm{C}$ for $45 \mathrm{~min}$. For stabilization, the gel was cooled immediately to an ambient temperature.

Honey (10\%): Honey solution @ 10g was dissolved in one liter of warm water to get honey $(10 \%)$ solution.

\section{Estimation of quality parameters}

Total anthocyanins (mg $\left.1 \mathbf{1 0 0 g}^{-1}\right)$ : The procedure outlined by Harborne (1973) was used for analyzing anthocyanin content in pomegranate arils. One gram of pomegranate arils was macerated in one millilitre of methanol containing one per cent hydrochloric acid. The content was kept overnight at $0^{\circ} \mathrm{C}$ temperature in a deep freezer. The absorbance of red colour solution was recorded at $530 \mathrm{~nm}$ on spectrophotometer. Anthocyanin content was expressed as absorption units at $530 \mathrm{~nm}$ per gram fresh arils.

The total anthocyanin content of arils was determined by using the following formula

Total optical density $/ \mathrm{mg}=\frac{\text { Optical density } \mathrm{x} \text { Volume made up } \mathrm{x} 100}{\text { Weight of the sample }}$

Total anthocyanins $(\mathrm{mg})=\frac{\text { Total optical density } / 100 \mathrm{~g}}{98.2}$

$\beta$-carotene content $\left(\mu \mathbf{1 0 0 g}^{-1}\right): \beta$-carotene 
content of pomegranate arils was estimated by using the methodology of Srivastava and Kumar (2002). $\beta$-carotene was extracted from the sample by crushing one gram of sample with $10 \mathrm{ml}$ acetone and adding crystals of anhydrous sodium sulphate. The supernatant was decanted and collected in a beaker. The process was repeated twice. $10 \mathrm{ml}$ of petroleum ether was added and mixed thoroughly. The content was transferred in to a separating funnel and two layers were separated out on standing solution. Lower layer was discarded and upper layer was collected and volume was made up to $20 \mathrm{ml}$ with petroleum ether. The optical density was recorded at $452 \mathrm{~nm}$ using petroleum ether as blank.

The $\beta$-carotene was estimated by using the formula

$\beta$-carotene $\left(\mu 100 \mathrm{~g}^{-1}\right)=\frac{\text { 0ptical Density X 13.9 X 10 } \mathrm{X100}}{\text { Weight of sample (g) X 560 X } 1000}$

\section{Sensory evaluation}

The stored arils of pomegranate were examined for their sensory qualities by assessing the colour, flavour, texture and overall acceptability. Sensory evaluation was carried out by a panel of 5 judges and the rating was done with score on 9 point Hedonic scale (Amerine et al., 1965). Organoleptic evaluation of pomegranate arils was carried out by Gil et al., (1996). The overall rating was obtained by averaging the score of evaluation. Fruits with sensory score of 5.5 and above were rated as acceptable.

\section{Results and Discussion}

\section{Total anthocyanins (mg $\left.100 \mathrm{~g}^{-1}\right)$}

In general, most of the pomegranate cultivars are predominant of cyanidin 3,5-diglucoside, while pelargonidin 3-glucoside anthocyanin was present in the lowest amount. Changes in the total anthocyanins were evaluated for all treatments across storage period. The results showed that with progressing storage duration, total anthocyanins declined throughout the storage period in all the treatments (Table.1). However, arils in control treatment (nonchitosan-coated arils) that were stored at $4^{\circ} \mathrm{C}$, $7{ }^{\circ} \mathrm{C}$ and room temperature $\left(26-29^{\circ} \mathrm{C}\right)$ showed an increase in total anthocyanins during initial days of storage but at the end of storage period, a rapid and considerable reduction was observed that reached the minimum value. In addition, a minor increase compared with that of control was recorded in coated pomegranates with $1 \%$ chitosan stored at $4^{\circ} \mathrm{C}$, $7{ }^{\circ} \mathrm{C}$ and room temperature $\left(26-29^{\circ} \mathrm{C}\right)$ during storage days and maintained better during 20 days of storage except, on $4^{\text {th }}$ day, minimum total anthocyanin $\left(\mathrm{mg} 100 \mathrm{~g}^{-1}\right)$ content (30.95) was recorded in $\mathrm{C}_{1}$ (1\% chitosan) coated arils was lower compared to un-coated arils in $\mathrm{C}_{4}$ (control) (33.86). Reduction of anthocyanin content recorded in this study was similar to those reported earlier by Ayhanand and Estruck (2009), Salama et al., (2012) and Caleb et al., (2013) in pomegranate and strawberries.

The maximum total anthocyanins $\left(\mathrm{mg}^{\left.100 \mathrm{~g}^{-1}\right)}\right.$ $(28.56,27.73,26.11)$ was observed in $\mathrm{C}_{1}(1 \%$ chitosan) and the minimum values (27.52, 25.84 and 24.03) were obtained in $\mathrm{C}_{4}$ (control) on $8^{\text {th }}, 12^{\text {th }}$ and $16^{\text {th }}$ day of storage, respectively. One per cent chitosan treatments showed better anthocyanin-keeping properties compared to control. This might be due to the barrier effect of the chitosan coating which imposes in its endogenous $\mathrm{CO}_{2}$ and $\mathrm{O}_{2}$ levels as reported by Zhang and Quantick (1998) in strawberries and raspberries. Chitosan application has also been demonstrated to have beneficial effects in maintaining anthocyanin content in several fruits such as longan fruit (Jiang and Li, 2001) and peeled litchi fruit (Donga et al., 2004).

The interaction effects between edible 
coatings and storage temperatures revealed that significant differences were observed on all the days of storage except, on $4^{\text {th }}$ and $12^{\text {th }}$ day of storage. $\mathrm{C}_{1} \mathrm{~T}_{1}\left(1 \%\right.$ chitosan and $\left.4 \pm 1^{\circ} \mathrm{C}\right)$ was found superior with regard to retention of total anthocyanins (mg 100 g-1) (29.72), (26.78) and $(25.38)$ on $8^{\text {th }}, 16^{\text {th }}$ and $20^{\text {th }}$ day of storage, respectively.

\section{Beta-carotene $\left(\mu 100 g^{-1}\right)$}

The influence of different edible coatings and storage temperatures $\beta$-carotene content $(\mu$ $100 \mathrm{~g}^{-1}$ ) of arils of pomegranate cv. Bhagwa was studied and the data is presented in Table. 2 . The $\beta$-carotene content $\left(\mu 100 \mathrm{~g}^{-1}\right)$ of arils decreased with increase in storage period. The highest $\beta$-carotene content in pomegranate arils $(29.68,28.36,28.03,26.35$ and 24.94) was recorded in $C_{1}$ (1\% chitosan) on $4^{\text {th }}, 8^{\text {th, }} 12^{\text {th }}, 16^{\text {th }}$ and $20^{\text {th }}$ day of storage, respectively.

The lowest $\beta$-carotene content $\left(\mu 100 \mathrm{~g}^{-1}\right)$ was recorded in $\mathrm{C}_{4}$ (control) $(27.93,27.91,26.57$, and 24.01). With regard to storage temperatures, $\mathrm{T}_{1}\left(4 \pm 1^{\circ} \mathrm{C}\right)$ recorded high $\beta$ carotene content $\left(\mu 100 \mathrm{~g}^{-1}\right)$ during storage period. Whereas, it was low at $\mathrm{T}_{3}$ (room temperature) on $4^{\text {th }}\left(26.42 \mu 100 \mathrm{~g}^{-1}\right)$ and $8^{\text {th }}$ $\left(25.06 \mu 100 \mathrm{~g}^{-1}\right)$ day of storage and the spoilage of arils observed after $8^{\text {th }}$ day of storage.

The interaction between edible coatings and storage temperatures had significant effect on $\beta$-carotene content $\left(\mu 100 \mathrm{~g}^{-1}\right)$ of arils. The highest $\beta$-carotene content $\left(\mu 100 \mathrm{~g}^{-1}\right)$ was recorded in $\mathrm{C}_{1} \mathrm{~T}_{1}\left(1 \%\right.$ chitosan and $\left.4 \pm 1^{\circ} \mathrm{C}\right)$ (31.26, 30.26, 28.65, 26.82 and 25.56). The lowest $\beta$-carotene content $\left(\mu 100 \mathrm{~g}^{-1}\right)(24.92)$ was recorded in $\mathrm{C}_{4} \mathrm{~T}_{3}$ (control and room temperature) on $4^{\text {th }}$ day of storage and spoilage of arils observed after $4^{\text {th }}$ day of storage.

\section{Organoleptic evaluation}

\section{Colour of pomegranate arils}

The colour of arils of pomegranate cv. Bhagwa was significantly influenced by edible coatings and storage temperatures Figure 1. It is evident from the data that a minor increase in aril colour was observed in un-coated arils compared with that of coated arils during initial days and steady decrease thereafter was noticed during storage period. Correlation between colour parameters and anthocyanin levels was reported in several fruits Jiang et al., 2005 in Litchi, Goncalves et al., 2007 in Cherries, Sepulveda et al., 2010 in pomegranate.

On $4^{\text {th }}$ day, minimum aril colour (8.21) was recorded in $\mathrm{C}_{1}(1 \%$ chitosan $)$ coated arils compared to un-coated arils in $\mathrm{C}_{4}$ (control) (8.59). Similar findings were also reported by Ayhanand and Estruck (2009) and Salama et al., (2012) in pomegranate, and also in strawberries and raspberries, where delayed colour change due to chitosan coating was observed by Han et al., (2004).

Maximum aril colour (8.03, 7.37, 6.78 and 6.26) observed on $8^{\text {th }}, 12^{\text {th }}, 16^{\text {th }}$ and $20^{\text {th }}$ day of storage with $\mathrm{C}_{1}$ (1\% chitosan) is due to low enzymatic activity and polyphenol oxidase (PPO) activity. The preservation of colour and retardation of browning have been improved by the use of films or coatings as stated by Olivas et al, 2009. Minimum aril colour (7.49, 6.00 and 5.78) was observed in $\mathrm{C}_{4}$ (control) on $8^{\text {th }}, 12^{\text {th }}$ and $16^{\text {th }}$ day of storage. The Interaction effects between edible coatings and storage temperatures revealed that significant differences were observed on all the days of storage except, on $4^{\text {th }}$ day of storage (Fig. 2). 


\section{Int.J.Curr.Microbiol.App.Sci (2018) 7(12): 1111-1121}

Table.1 Effect of different edible coatings and storage temperatures on total anthocyanin content ( $\left.\mathrm{mg} 100 \mathrm{~g}^{-1}\right)$ of arils of pomegranate cv. Bhagwa

\begin{tabular}{|c|c|c|c|c|c|c|c|c|c|c|c|c|c|c|c|c|c|c|c|c|c|c|c|c|c|c|}
\hline \multicolumn{27}{|c|}{ Total anthocyanin content $\left(\mathrm{mg} 100 \mathrm{~g}^{-1}\right)$} \\
\hline \multicolumn{27}{|c|}{ Storage period (days) } \\
\hline & $\mathbf{0}$ & \multicolumn{5}{|c|}{4} & \multicolumn{5}{|c|}{8} & \multicolumn{5}{|c|}{12} & \multicolumn{5}{|c|}{16} & \multicolumn{5}{|c|}{20} \\
\hline & & $\mathbf{C}_{1}$ & $\mathbf{C}_{2}$ & $\mathbf{C}_{3}$ & $\mathbf{C}_{4}$ & Mean & $\mathbf{C}_{1}$ & $\mathbf{C}_{2}$ & $\mathbf{C}_{3}$ & $\mathbf{C}_{4}$ & Mean & $\mathbf{C}_{1}$ & $\mathbf{C}_{2}$ & $\mathbf{C}_{3}$ & $\mathbf{C}_{4}$ & Mean & $\mathbf{C}_{1}$ & $\mathbf{C}_{2}$ & $\mathbf{C}_{3}$ & $\mathbf{C}_{4}$ & Mean & $\mathbf{C}_{1}$ & $\mathbf{C}_{2}$ & $\mathbf{C}_{3}$ & $\mathbf{C}_{4}$ & Mean \\
\hline $\mathrm{T}_{1}$ & 29.31 & 30.06 & 30.18 & 30.13 & 30.77 & 30.28 & 29.72 & 29.60 & 29.67 & 28.03 & 29.25 & 28.18 & 28.11 & 28.16 & 26.33 & 27.69 & 26.78 & 26.71 & 26.75 & 24.03 & 26.07 & 25.38 & 25.27 & 25.31 & $*$ & 25.32 \\
\hline $\mathrm{T}_{2}$ & 29.31 & 30.76 & 30.82 & 30.78 & 31.27 & 30.90 & 28.88 & 28.78 & 28.82 & 27.01 & 28.37 & 27.28 & 27.16 & 27.21 & 25.36 & 26.75 & 25.44 & 25.38 & 25.40 & $*$ & 25.41 & 24.14 & 24.06 & 24.11 & $*$ & 24.10 \\
\hline $\mathrm{T}_{3}$ & 29.31 & 32.02 & 32.15 & 32.10 & 33.86 & 32.53 & 27.12 & 27.07 & 27.09 & $*$ & 27.09 & $*$ & $*$ & $*$ & $*$ & $*$ & $*$ & $*$ & $*$ & $*$ & $*$ & $*$ & $*$ & $*$ & $*$ & $*$ \\
\hline Mean & 29.31 & 30.95 & 31.05 & 31.03 & 31.97 & & 28.57 & 28.48 & 28.53 & 27.52 & & 27.73 & 27.66 & 27.68 & 25.84 & & 26.11 & 26.04 & 26.07 & 24.03 & & 24.76 & 24.66 & 24.71 & $*$ & \\
\hline \multicolumn{2}{|c|}{ Statistics } & \multicolumn{2}{|c|}{ SE.m \pm} & \multicolumn{3}{|c|}{ CD @ $\mathrm{P}=\mathbf{0 . 0 5}$} & \multicolumn{2}{|c|}{ SE.m \pm} & \multicolumn{3}{|c|}{ CD @ P=0.05 } & \multicolumn{2}{|c|}{ SE.m \pm} & \multicolumn{3}{|c|}{ CD @ $\mathrm{P}=\mathbf{0 . 0 5}$} & \multicolumn{2}{|c|}{ SE.m \pm} & \multicolumn{3}{|c|}{ CD @ P=0.05 } & \multicolumn{2}{|c|}{ SE.m \pm} & \multicolumn{3}{|c|}{ CD @ P=0.05 } \\
\hline & $\mathrm{C}$ & \multicolumn{2}{|c|}{0.28} & \multicolumn{3}{|c|}{0.83} & \multicolumn{2}{|c|}{0.25} & \multicolumn{3}{|c|}{0.74} & \multicolumn{2}{|c|}{0.21} & \multicolumn{3}{|c|}{0.62} & \multicolumn{2}{|c|}{0.18} & \multicolumn{3}{|c|}{0.52} & \multicolumn{2}{|c|}{0.14} & \multicolumn{3}{|c|}{0.42} \\
\hline & $\mathrm{T}$ & \multicolumn{2}{|c|}{0.24} & \multicolumn{3}{|c|}{0.72} & 0. & & & 0.66 & & 0 . & 18 & & 0.54 & & 0. & 16 & & 0.45 & & 0 . & 12 & & 0.36 & \\
\hline & $\mathrm{C} \times \mathrm{T}$ & & 49 & & NS & & 0. & & & 1.29 & & 0. & 37 & & NS & & 0. & 31 & & 0.91 & & 0. & 25 & & 0.72 & \\
\hline
\end{tabular}

$\mathrm{T}_{1}: 4 \pm 1^{0} \mathrm{C}$

$\mathrm{T}_{2}: 7 \pm 1^{0} \mathrm{C}$

$\mathrm{C}_{2}:$ : Aloe vera gel $(100 \%)$

$\mathrm{C}_{3}:$ Honey $(10 \%)$

$\mathrm{C}_{4}$ : Control (Un-treated)
* Decayed arils 


\section{Int.J.Curr.Microbiol.App.Sci (2018) 7(12): 1111-1121}

Table. 2 Effect of different edible coatings and storage temperatures on beta-carotene content $\left(\mu 100 \mathrm{~g}^{-1}\right)$ of arils of pomegranate cv. Bhagwa

\begin{tabular}{|c|c|c|c|c|c|c|c|c|c|c|c|c|c|c|c|c|c|c|c|c|c|c|c|c|c|c|}
\hline \multicolumn{27}{|c|}{ Beta-carotene content $\left(\boldsymbol{\mu} 100 \mathrm{~g}^{-1}\right)$} \\
\hline \multicolumn{27}{|c|}{ Storage period (days) } \\
\hline & $\mathbf{0}$ & \multicolumn{5}{|c|}{4} & \multicolumn{5}{|c|}{8} & \multicolumn{5}{|c|}{12} & \multicolumn{5}{|c|}{16} & \multicolumn{5}{|c|}{20} \\
\hline & & $\mathrm{C}_{1}$ & $\mathbf{C}_{2}$ & $\mathbf{C}_{3}$ & $\mathbf{C}_{4}$ & Mean & $\mathbf{C}_{1}$ & $\mathbf{C}_{2}$ & $\mathbf{C}_{3}$ & $\mathbf{C}_{4}$ & Mean & $\mathrm{C}_{1}$ & $\mathbf{C}_{2}$ & $\mathbf{C}_{3}$ & $\mathrm{C}_{4}$ & Mean & $\mathrm{C}_{1}$ & $\mathbf{C}_{2}$ & $\mathbf{C}_{3}$ & $\mathbf{C}_{4}$ & Mean & $\mathrm{C}_{1}$ & $\mathbf{C}_{2}$ & $\mathbf{C}_{3}$ & $\mathrm{C}_{4}$ & Mean \\
\hline $\mathrm{T}_{1}$ & 32.07 & 31.26 & 31.23 & 31.25 & 30.02 & 30.94 & 30.26 & 30.20 & 30.24 & 28.38 & 29.77 & 28.65 & 28.52 & 28.61 & 27.11 & 28.22 & 26.82 & 26.78 & 26.80 & 24.01 & 26.10 & 25.56 & 25.50 & 25.53 & $*$ & 25.53 \\
\hline $\mathrm{T}_{2}$ & 32.07 & 30.82 & 30.79 & 30.80 & 28.86 & 30.31 & 29.72 & 29.68 & 29.70 & 27.45 & 29.13 & 27.42 & 27.37 & 27.40 & 26.04 & 27.06 & 25.65 & 25.60 & 25.62 & $*$ & 25.62 & 24.32 & 24.28 & 24.30 & * & 24.30 \\
\hline $\mathrm{T}_{3}$ & 32.07 & 26.96 & 26.90 & 26.91 & 24.92 & 26.42 & 25.11 & 25.01 & 25.08 & * & 25.06 & * & * & $*$ & * & * & * & * & * & * & $*$ & * & * & $*$ & $*$ & $*$ \\
\hline Mean & 32.07 & 29.68 & 29.64 & 29.65 & 27.93 & & 28.36 & 28.30 & 28.34 & 27.91 & & 28.03 & 27.94 & 28.00 & 26.57 & & 26.35 & 26.19 & 26.21 & 24.01 & & 24.94 & 24.84 & 24.91 & * & \\
\hline \multicolumn{2}{|c|}{ Statistics } & \multicolumn{2}{|c|}{ SE.m \pm} & \multicolumn{3}{|c|}{ CD @ P=0.05 } & \multicolumn{2}{|c|}{ SE.m \pm} & \multicolumn{3}{|c|}{ CD @ P=0.05 } & \multicolumn{2}{|c|}{ SE.m \pm} & \multicolumn{3}{|c|}{ CD @ P=0.05 } & \multicolumn{2}{|c|}{ SE.m \pm} & \multicolumn{3}{|c|}{ CD @ P=0.05 } & \multicolumn{2}{|c|}{ SE.m \pm} & \multicolumn{3}{|c|}{ CD @ P=0.05 } \\
\hline & C & \multicolumn{2}{|c|}{0.27} & \multicolumn{3}{|c|}{0.79} & \multicolumn{2}{|c|}{0.26} & \multicolumn{3}{|c|}{0.74} & \multicolumn{2}{|c|}{0.22} & \multicolumn{3}{|c|}{0.63} & 0 & 18 & \multicolumn{3}{|c|}{0.53} & 0. & 17 & \multicolumn{3}{|c|}{0.48} \\
\hline & $\mathrm{T}$ & \multicolumn{2}{|c|}{0.23} & \multicolumn{3}{|c|}{0.68} & \multicolumn{2}{|c|}{0.22} & \multicolumn{3}{|c|}{0.64} & 0 & & & 0.55 & & 0 & 16 & & 0.46 & & 0. & & & 0.42 & \\
\hline & $\mathrm{C} \times \mathrm{T}$ & & 47 & & NS & & & 44 & & 1.29 & & 0 & & & NS & & 0 & 31 & & 0.91 & & 0. & & & 0.84 & \\
\hline
\end{tabular}

$\mathrm{C}_{1} \quad$ : $\quad$ Chitosan (1\%)

$\mathrm{C}_{2}$ : Aloe vera gel (100\%)

$\mathrm{C}_{3}:$ Honey $(10 \%)$

$\mathrm{C}_{4} \quad$ : Control (Un-treated)
$\mathrm{T}_{1}: 4 \pm 1^{0} \mathrm{C}$

$\mathrm{T}_{2}: 7 \pm 1^{0} \mathrm{C}$

$\mathrm{T}_{3} \quad: \quad$ Room temperature $\left(26-29^{0} \mathrm{C}\right)$
* Decayed arils 


\section{Int.J.Curr.Microbiol.App.Sci (2018) 7(12): 1111-1121}

Table.3 Effect of different edible coatings and storage temperatures on flavour of arils of pomegranate cv. Bhagwa

\begin{tabular}{|c|c|c|c|c|c|c|c|c|c|c|c|c|c|c|c|c|c|c|c|c|c|c|c|c|c|c|}
\hline \multicolumn{27}{|c|}{ Flavour of arils (organoleptic score) } \\
\hline \multicolumn{27}{|c|}{ Storage period (days) } \\
\hline & $\mathbf{0}$ & \multicolumn{5}{|c|}{4} & \multicolumn{5}{|c|}{8} & \multicolumn{5}{|c|}{12} & \multicolumn{5}{|c|}{16} & \multicolumn{5}{|c|}{20} \\
\hline & & $\mathbf{C}_{1}$ & $\mathbf{C}_{2}$ & $\mathbf{C}_{3}$ & $\mathbf{C}_{4}$ & Mean & $\mathbf{C}_{1}$ & $\mathrm{C}_{2}$ & $\mathrm{C}_{3}$ & $\mathbf{C}_{4}$ & Mean & $\mathbf{C}_{1}$ & $\mathrm{C}_{2}$ & $\mathbf{C}_{3}$ & $\mathrm{C}_{4}$ & Mean & $\mathbf{C}_{1}$ & $\mathbf{C}_{2}$ & $\mathbf{C}_{3}$ & $\mathbf{C}_{4}$ & Mean & $\mathbf{C}_{1}$ & $\mathbf{C}_{2}$ & $\mathbf{C}_{3}$ & $\mathbf{C}_{4}$ & Mean \\
\hline $\mathrm{T}_{1}$ & 8.90 & 8.86 & 8.83 & 8.84 & 8.01 & 8.63 & 8.68 & 8.61 & 8.67 & 7.31 & 8.32 & 7.78 & 7.72 & 7.76 & 7.01 & 7.57 & 7.38 & 7.32 & 7.36 & 5.61 & 6.91 & 6.64 & 6.57 & 6.61 & $*$ & 6.60 \\
\hline $\mathrm{T}_{2}$ & 8.90 & 8.37 & 8.27 & 8.34 & 7.66 & 8.16 & 8.19 & 8.16 & 8.17 & 6.55 & 7.77 & 7.06 & 7.01 & 7.03 & 5.32 & 6.60 & 6.56 & 6.51 & 6.53 & $*$ & 6.53 & 5.62 & 5.56 & 5.58 & $*$ & 5.59 \\
\hline $\mathrm{T}_{3}$ & 8.90 & 6.11 & 6.06 & 6.08 & 5.33 & 5.90 & 5.43 & 5.36 & 5.39 & $*$ & 5.93 & $*$ & $*$ & $*$ & $*$ & $*$ & $*$ & $*$ & $*$ & $*$ & $*$ & $*$ & $*$ & $*$ & $*$ & $*$ \\
\hline Mean & 8.90 & 7.78 & 7.72 & 7.75 & 7.00 & & 7.43 & 7.38 & 7.41 & 6.93 & & 7.42 & 7.36 & 7.39 & 6.16 & & 6.97 & 6.91 & 6.94 & 5.61 & & 6.13 & 6.06 & 6.09 & $*$ & \\
\hline \multicolumn{2}{|c|}{ Statistics } & \multicolumn{2}{|c|}{ SE.m \pm} & \multicolumn{3}{|c|}{$\mathrm{CD} @ \mathbf{P}=0.05$} & \multicolumn{2}{|c|}{ SE.m \pm} & \multicolumn{3}{|c|}{$\mathrm{CD} @ P=0.05$} & \multicolumn{2}{|c|}{ SE.m \pm} & \multicolumn{3}{|c|}{ CD @ $9=0.05$} & \multicolumn{2}{|c|}{ SE.m \pm} & \multicolumn{3}{|c|}{$C D @ P=0.05$} & \multicolumn{2}{|c|}{ SE.m \pm} & \multicolumn{3}{|c|}{$C D @ P=0.05$} \\
\hline & $\mathrm{C}$ & \multicolumn{2}{|c|}{0.07} & \multicolumn{3}{|c|}{0.21} & \multicolumn{2}{|c|}{0.07} & \multicolumn{3}{|c|}{0.19} & \multicolumn{2}{|c|}{0.05} & \multicolumn{3}{|c|}{0.16} & \multicolumn{2}{|c|}{0.05} & \multicolumn{3}{|c|}{0.13} & \multicolumn{2}{|c|}{0.03} & \multicolumn{3}{|c|}{0.10} \\
\hline & $\mathrm{T}$ & & & & 0.18 & & 0. & & & 0.17 & & 0. & & & 0.14 & & & & & 0.12 & & 0. & & & 0.09 & \\
\hline & $\mathrm{C} \times \mathrm{T}$ & & & & NS & & 0. & & & 0.33 & & 0. & & & 0.28 & & 0. & & & 0.23 & & 0.1 & & & 0.18 & \\
\hline & $\mathrm{C}_{1}$ & : & Chito & an $(1$ & & & & $\mathrm{T}_{1}$ & $4 \pm$ & ${ }^{0} \mathrm{C}$ & & & & & & $*$ & Decay & $\mathrm{d}$ aril & & & & & & & & \\
\hline & $\mathrm{C}_{2}$ & : & Aloe & era $g$ & $1(100$ & & & $\mathrm{T}_{2}$ & $7 \pm$ & & & & & & & & & & & & & & & & & \\
\hline & $\mathrm{C}_{3}$ & : & Hone & $(10 \%$ & & & & $\mathrm{T}_{3}$ & Ro & $\mathrm{m}$ tem & perature & $(26-2$ & $\left.{ }^{0} \mathrm{C}\right)$ & & & & & & & & & & & & & \\
\hline & $\mathrm{C}_{4}$ & : & Contr & 1 (Un & treate & & & & & & & & & & & & & & & & & & & & & \\
\hline
\end{tabular}


Fig.1 Effect of different edible coatings and storage temperatures on aril colour of pomegranate cv. Bhagwa

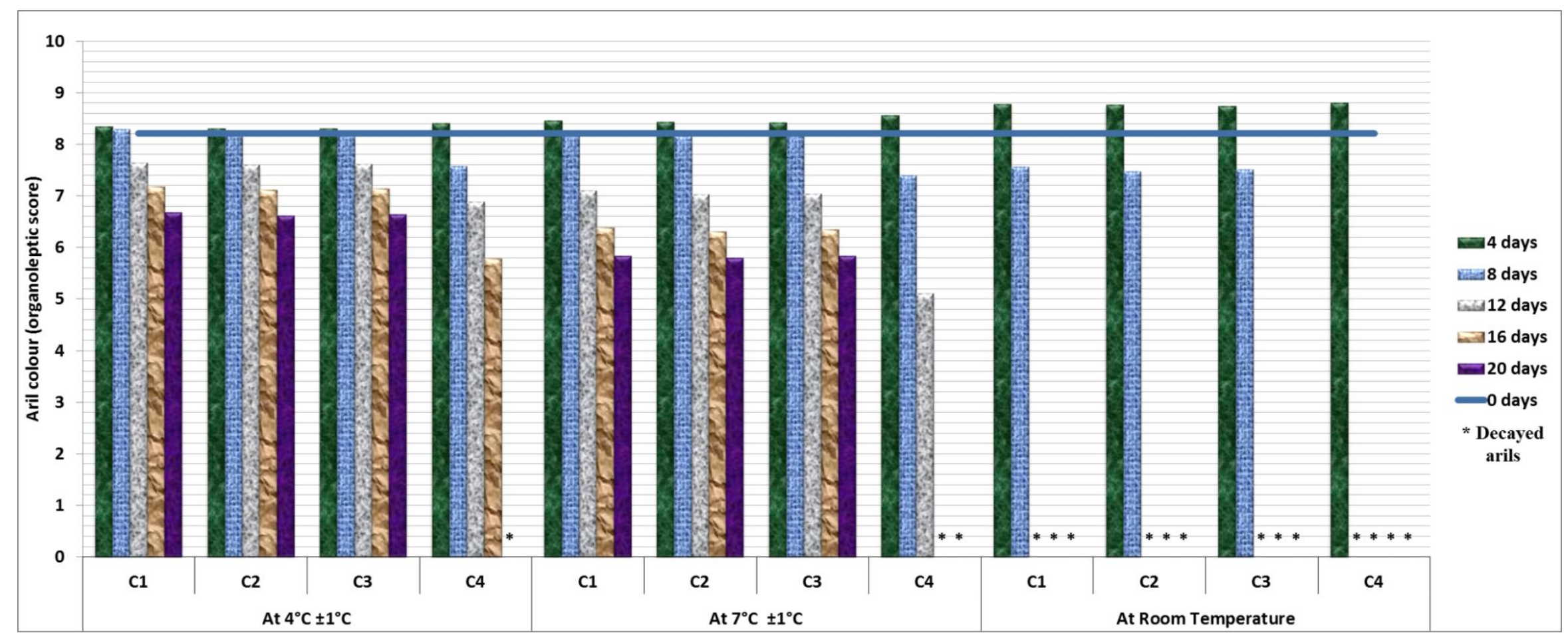


Among the storage temperatures, $\mathrm{T}_{1}\left(4 \pm 1^{0} \mathrm{C}\right)$ was found significantly superior with regard to retention of aril colour $(8.34,8.10,7.44$, 6.80 and 6.64) on $4^{\text {th }}, 8^{\text {th }}, 12^{\text {th }}, 16^{\text {th }}$ and $20^{\text {th }}$ day of storage. Maximum aril colour score recorded in $T_{3}$ (room temperature) on $4^{\text {th }}$ (8.77) might be due to high enzymatic activity, and minimum at $8^{\text {th }}$ (7.51) day of storage and spoilage was observed after 8 days of storage. The colour change observed in the present study might be due to lower enzymatic activity which is most likely related to arils stored at lower temperatures.

\section{Taste of pomegranate arils}

There was a reducing trend in organoleptic score of taste of arils during the period of storage and this might be due to fluctuations in acids, $\mathrm{pH}$ and sugar/acid ratio as reported by Malundo et al., (1997) in mango. The small variation in taste scores of treated pomegranate arils was for chitosan coating, which maintained taste and retained the quality until 20 days of storage. Munoz et al., (2006) stated that, the influence of the chitosan on strawberries stored at $20^{\circ} \mathrm{C}$ for 4 days showed better maintenance of eating quality. The best organoleptic score for aril taste was recorded in $\mathrm{C}_{1}$ (1\% chitosan) and the least score was recorded in $\mathrm{C}_{4}$ (control). The low temperature maintained the aril quality which influenced the aril taste Figure 3. Jiang and $\mathrm{Li}$, (2001) reported that chitosan treated longan fruit had good eating quality even after 30 days of storage at $2^{\circ} \mathrm{C}$. The interaction effect between coatings and temperatures revealed that the organoleptic score for taste of arils was maximum in $\mathrm{C}_{1} \mathrm{~T}_{1}(1 \%$ chitosan and $4 \pm 1^{\circ} \mathrm{C}$ ) and the minimum organoleptic score for this trait was recorded in $\mathrm{C}_{4} \mathrm{~T}_{3}$ (control and room temperature).

\section{Flavour of pomegranate arils}

The organoleptic score for flavor of arils of pomegranate $\mathrm{cv}$. Bhagwa as influenced by edible coatings and storage temperatures are presented in Table.3. There was a decreasing trend in flavor score of arils throughout the storage period. The best flavor score for arils was recorded in $\mathrm{C}_{1}$ (1\% chitosan) during 20 days of storage. The maximum off flavor with least flavor score was recorded in $\mathrm{C}_{4}$ (control). These results tally with Munoz et al., (2006) and Sayak et al., (2014) who reported influence of chitosan for better maintenance of eating quality in pineapple and strawberries. The best flavor score of arils was recorded in $\mathrm{T}_{1}\left(4 \pm 1^{\circ} \mathrm{C}\right)$. With regard to interaction effects, significant differences were observed between edible coatings and storage temperatures for all the storage days except, $4^{\text {th }}$ day, which was found nonsignificant. The best flavor score of arils was recorded in $\mathrm{C}_{1} \mathrm{~T}_{1}\left(1 \%\right.$ chitosan and $\left.4 \pm 1^{\circ} \mathrm{C}\right)$ during 20 days of storage. Similar findings were also reported by Doreyappa and Huddar (2001) in mango.

Based on the results obtained from the study, it is concluded that chitosan (1\%) edible coating to arils of pomegranate cv. Bhagwa proved to be good in maintaining the quality of arils during storage period of twenty days. Integrating chitosan $(1 \%)$ treated arils with cold storage temperature of $4 \pm 1^{\circ} \mathrm{C}$, was found to be promising in maintaining several quality parameters such as total anthocyanins, $\beta$ carotene $\left(\mu 100 \mathrm{~g}^{-1}\right)$, and organoleptic scores.

\section{Acknowledgment}

This work was supported by Dr. Y.S.R. Horticultural University, Venkataramannagudem West Godavari District, Andhra Pradesh.

\section{References}

Amerine, M.A, Pangborn, R.M. and Rossler, B.B. 1965. Principles of sensory evaluation of food. Academic press, London. 
Ayhan, Z., and Esturk, O. 2009. Overall quality and shelf life of minimally processed and modified atmosphere packaged ready-to-eat pomegranate arils. Journal of Food Science. 74(5):399-405.

Caleb, O.J, Oparaa, U.L, Pramod, V, Mahajan, Manley, M, Lucky, M. and Andreas, G.J. 2013. Effect of modified atmosphere packaging and storage temperature on volatile composition and postharvest life of minimally processed pomegranate arils cv.'Acco' and 'Herskawitz'. Post-harvest Biology and Technology. 79: 54-61.

Chien, P.J, Sheu, F. and Lin, H.R. 2007. Coating citrus (Murcott tangor) fruit with low molecular weight chitosan increases postharvest quality and shelf life. Food Chemistry. 100:1160-1164.

Doreyappa, G., and Huddar, A.G. 2001. Studies on ripening changes in mango fruits. Journal of Food Science and Technology. 38: 135-137.

El-Ghaouth, Ponnampalam, A.R, Castaigne, F. and Arul, J. 1992. Chitosan coating to extend the storage life of tomatoes. Horticultural Science. 27: 1016-18.

Fawole, O.A, Opara, V.L and Theron, K.I. 2012. Chemical and phytochemical properties and antioxidant activities of three pomegranate cultivars grown in South Africa. Food Bioprocess and Technology. 5: 425-444.

Gil, M.I, Juan, A, Martinez and Francisco, Artes. 1996. Minimally processed pomegranate seeds. Food Science and Technology Department, 29:708-13.

Goncalves, B., Silva, A.P, Moutinho-Pereira, J, Bacelar, E, Rosa, E, Meyer, A.S. 2007. Effect of ripeness and postharvest storage on the evolution of colour and anthocyanins in cherries (Prunu savium L.). Food Chemistry. 103(3): 976-984.

Han, C., Zhao, Y, Leonard, S.W, Traber, M.G. 2004. Edible coating to improve storability and enhance nutritional value of fresh and frozen strawberries (Fragaria ananassa) and raspberries (Rubus ideaus). Postharvest Biology Technology. 33 (1):67-78.

Harborne, J.B. 1973. Phytochemical methods. Chapman and Haul International Ed. Toppan Co. Ltd. Tokyo, Japan.

Jiang, Y., Li, J, Jiang, W. 2005. Effects of chitosan coating on shelf life of coldstored litchi fruit at ambient temperature. Food Science and Technology. 38(7): 757-761.

Jiang, Y., and Li, Y. 2001. Effect of chitosan coating on post-harvest life and quality of longan fruit. Food Chemistry: 73: 139-143.

Malundo, T.M.M, Baldwin, E.A, Moshonas, M.G, Baker, R.A. and Shewfelt, R.L. 1997. Method for the rapid headspace analysis of mango (Mangifera indica L.) homogenate volatile constituents and factors affecting quantitative results. Journal of Agricultural Food Chemistry. 45(6): 2187-2194.

Munoz, H.P, Almenar, E, Ocio, M.J. and Gavara, R. 2006. Effect of calcium dips and chitosan coating on post-harvest life of strawberries (Fragaria $\times$ ananassa). Postharvest Biology and Technology. 39: 247-253.

Muzzarelli, R.A.A. and Rocchetti, R. 1985. Determination of the degree of acetylation of chitosans by first derivative ultraviolet spectrophotometry. Food Science and Technology Department. 5: 461-72.

Nanda, S., Rao, D.V.S, Krishnamurthy, S. 2001. Effects of shrink film wrapping and storage temperature on the shelf life and quality of pomegranate fruits $\mathrm{cv}$. Ganesh. Postharvest Biology and Technology. 22 (1): 61-69.

Olivas, G.I. and Canovas, B.G. 2009. Edible films and coatings for fruits and vegetables. Embuscado and K.C. Huber 
(eds.). Edible Films and Coatings for Food Application. 211-38.

Rathod, A., Shoba, H. and Chidanand, D.V. 2011. A study on shelf life extension of Carambola Fruits. International Journal of Scientific \& Engineering Research. 2 (9): 2229-5518.

Salama, M.E.I, Ayaad, H.M, Aboul-Anean, H.E. and Fahmy, H.M. 2012. Effect of edible coating as a carrier of essential oils and ultraviolet light (UV-C) on improving quality of minimally processed Manfalouty pomegranate. Research Journal of Agriculture and Biological Sciences. 8(2):315-324.

Sayka, M., Ibrahim, Shamsun, N, Jahid, M.M, Islam, Mahfuza Islam, M.M, Hoque, R. and Mubarak, A.K. 2014. Effect of low molecular weight chitosan coating on physico-chemical properties and shelf life extension of pineapple (Ananas sativus). Journal of Forest Products and Industries. 3(3):161-166.
Sepulveda, E, Saenz, C, Pena, A, Robert, P, Bartolome, B. and Gomez-Cordoves, C. 2010. Influence of the genotype on the anthocyanin composition, antioxidant capacity and colour of Chilean pomegranate (Punica granatum L.) juices. Chilean Journal of Agricultural Research. 70: 50-57.

Srivastava, R.P. and Kumar, S. 2002. Fruit and vegetable preservation, principles and practices. $3^{\text {rd }}$ edition revised and enlarged edition. Bio-green Books.

Vinda-Maros, M., Fernandez, L.J, Perez, A.J.A.2010. Pomegranate and its many functional components as related to human health. Food Science and Safety. 9:635-665.

Zhang, D.L. and Quantick, P.C. 1998. Antifungal effects of chitosan coating on fresh strawberries and raspberries during storage. Journal of Horticulture Science and Biotechnology. 73: 763-67.

\section{How to cite this article:}

Viswanath, M., K. Venkataramudu, B. Srinivasulu, K. Swarajya Lakshmi, K. Gopal and Balakrishna, M. 2018. Bioactive Compounds and Quality Attributes of Edible Coated Readyto-Eat Arils of Pomegranate cv. Bhagwa Packed in Clamshells during Storage. Int.J.Curr.Microbiol.App.Sci. 7(12): 1111-1121. doi: https://doi.org/10.20546/ijcmas.2018.712.137 